EGU2020-12057

https://doi.org/10.5194/egusphere-egu2020-12057

EGU General Assembly 2020

(c) Author(s) 2020. This work is distributed under

the Creative Commons Attribution 4.0 License.

\title{
Soil degradation due to the conversion of native grassland into cropland in the Pampa biome - (Southern Brazil) and impact on suspended sediment supply to the rivers
}

\author{
Rafael Ramon ${ }^{1,2}$, Olivier Evrard ${ }^{2}$, Tales Tiecher ${ }^{1}$, Sylvain Huon ${ }^{3}$, Felipe Bernardi ${ }^{4}$, Antônio A. M. \\ Batista $^{5}$, Tadeu L. Tiecher ${ }^{6}$, Véronique Vaury ${ }^{3}$, and Jean Minella ${ }^{4}$ \\ ${ }^{1}$ Federal University of Rio Grande do Sul, Agronomy Faculty, Postgraduate Program in Soil Science, Porto Alegre, Brazil \\ (rafaramon11@gmail.com) \\ ${ }^{2}$ Laboratoire des sciences du climat et de l'environnement, Université Paris-Saclay, CNRS, CEA, UVSQ. 91191, Gif-sur-Yvette, \\ France. \\ ${ }^{3}$ Sorbonne Universités UPMC Univ Paris 06, Institut d'Ecologie et des Sciences de l'environnement de Paris (iEES), 4 place \\ Jussieu, 75252 Paris cedex 05, France \\ ${ }^{4}$ Graduate Program in Soil Science, Soil Department, Federal University of Santa Maria, Roraima Ave. 1000, 97105-900 Santa \\ Maria, RS, Brazil \\ ${ }^{5}$ Farroupilha Federal Institute of Education, Science and Technology (IFFar), 97555-000 Alegrete, RS, Brazil \\ ${ }^{6}$ Rio Grande do Sul Federal Institute, Campus Restinga, 91791-508, Porto Alegre, RS, Brazil
}

The conversion of the natural grasslands of the Pampa biome (Southern Brazil) into cropland may lead to an increase in soil erosion rates and sediment delivery to the rivers. Grasslands represent a significant sink of carbon, and according to the literature, $59 \%$ of the soil organic carbon (SOC) is lost when pastures are converted into cropland. It makes soils even more vulnerable to water and land degradation. This study aims to evaluate the impact of land use change on the river sediment composition by calculating the sediment contribution of each potential sediment source using organic matter composition, ultra-violet and visible (UV-VIS) spectra derived parameters and fallout radionuclide activities, as potential tracers in a sediment fingerprinting approach. The study site (Ibirapuitã river basin -5,942 $\mathrm{km}^{2}$ ) is located in the Pampa biome, Southern Brazil, were sandy and shallow soils predominate, occupied mainly by native grasslands that are gradually being converted to cropfields, especially soybean. Potential sediment sources were sampled, which include croplands $(n=36)$, native grasslands $(n=31)$, unpaved roads $(n=31)$ and subsurface sources (channel banks $(n=18)$ and gullies $(n=16)$ ). Samples were taken from the soil surface layer of croplands and grasslands, as well as from the top layer of exposed sites of gullies, channel banks and unpaved roads. Samples were oven dried $\left(50^{\circ} \mathrm{C}\right)$, gently disaggregated and dry sieved to 63 $\mathrm{mm}$ to avoid particle size effects prior to further analysis. Suspended sediment samples were collected using time integrated samplers deployed in the bottom of the river, and during rainfall runoff events at the outlet of the catchment. Organic matter parameters (total organic carbon TOC, total nitrogen - TN, $\delta^{13} \mathrm{C}$ and $\delta^{15} \mathrm{~N}$ ) were measured using a continuous flow isotope ratio mass spectrometry (EA-IRMS). Diffuse reflectance spectra in the UV-VIS wavelengths was measured using a Cary 5000 UV-VIS-NIR spectrophotometer, and 33 parameters were derived from the 
spectra. Fallout radionuclide $\left({ }^{137} \mathrm{Cs}\right.$ and $\left.{ }^{210} \mathrm{~Pb}_{\mathrm{xs}}\right)$ activities were measured by gamma spectrometry using low-background high-purity germanium detectors. Tracers were selected following a three step procedure, including: (i) a conservative range test, (ii) a Kruskal-Wallis $\mathrm{H}$-test, and (iii) a linear discriminant function analysis. The selected tracers were introduced into a mass balance mixing model to estimate the source contributions to in-stream sediment by minimizing the sum of square residuals. TOC and TN show significant differences between cropland and native grassland, while the isotopes $\delta^{13} \mathrm{C}$ and $\delta^{15} \mathrm{~N}$, presented a lower discrimination potential. TOC and UV-VIS derived parameters did not present a good discriminant potential when they were tested in isolation, although they increased the source discrimination when combined with organic matter parameters. Fallout radionuclides have a good discriminant potential between surface and subsurface sources, but also between native grasslands and croplands. Croplands are the main sediment source in the Ibirapuitã river catchment (36\%), followed by the native grasslands (33\%). However, the area occupied by croplands is approximately eight times smaller, demonstrating that erosion processes have been intensified by the conversion of native grasslands into croplands and/or croplands are better connected to the river network. 